\title{
DA HARMONIA AO CONFLITO: A Delegacia Regional do Trabalho em Alagoas (1956-1959)
}

Anderson Vieira Moura*

\section{RESUMO:}

Em 1956, Edson Falcão retornava ao cargo de delegado Regional do Trabalho em Alagoas. Nessa segunda vez, chegou até a compor a mesa em reuniões do maior sindicato têxtil do estado para expor seu programa de trabalho e ouvir os operários. Falcão era figura recorrente em reuniões sindicais, além de ter proximidade e apoio do então governador Muniz Falcão. Contudo, sua atuação à frente da Delegacia Regional do Trabalho (DRT) chegou a um momento crucial após conflitos políticopartidários (indiretos) com governador, acabando por desgastar também sua relação com os trabalhadores. O objetivo desse artigo é analisar algumas atuações do delegado do Trabalho e como ocorreu seu declínio na função, através de atas sindicais, reportagens de jornais, processos trabalhistas e uma entrevista feita com seu primogênito.

Palavras-chave: Delegacia Regional do Trabalho; operários têxteis; sindicatos.

\begin{abstract}
:
In 1956, Edson Falcão returned to the post of regional labor delegate in Alagoas. The second time around, he composed the table in meetings of the largest textile state union to expose its work program and hear the workers. Falcão was a recurring figure in union meetings, in addition to proximity and support Governor Muniz Falcão. However, his performance ahead of the Regional Labor Office (DRT) has reached a turning point after party-political conflicts (indirect) with governor, eventually also wear their relationship with workers. The aim of this paper is to analyze some performances Delegate of Labor and how did their decline in function, through union acts, newspaper reports, lawsuits and an interview with his firstborn.
\end{abstract}

Keywords: Regional Labor Office; Textile workers; Trade unions.

$\mathrm{Na}$ historiografia acerca dos operários no período democrático (1945-1964), encontramos, via de regra, dois tipos de citações à Delegacia Regional do Trabalho (DRT): queixas dos trabalhadores quanto à ineficiência da fiscalização ou o órgão mediando tentativas de conciliação entre patrões e empregados, antes de um dos lados (ou os dois) irem à Justiça do Trabalho. Em Alagoas, as fontes disponíveis não indicaram nada disso. Muito pelo contrário: veremos o uso político-partidário da DRT local, com as questões trabalhistas quase sempre em segundo plano. A DRT alagoana servia mais para propagar os ideais do Partido Trabalhista Brasileiro (PTB) entre o operariado do que garantir o cumprimento das leis. A ideia central deste artigo é discutir a atuação da DRT alagoana na segunda metade dos

\footnotetext{
"Doutor em História Social pela Universidade Estadual de Campinas. Mestre em História pela Universidade Federal de Pernambuco. Graduado em História pela Universidade Federal de Alagoas. E-mail: anderson_vm@yahoo.com.br
} 
anos 1950, sobretudo sua relação de proximidade e posteriormente de conflito com o governo. Assim, é possível perceber de maneira mais clara a presença de um membro do Estado no seio do movimento operário.

As delegacias surgiram com o Decreto-Lei no 2.168, de 6 de maio de 1940, quando Getúlio Vargas e o então ministro do Trabalho Valdemar Falcão transformaram as Inspetorias Regionais do Ministério do Trabalho, Indústria e Comércio em Delegacias Regionais do Trabalho, criando assim o cargo de delegado do Trabalho "com atribuições, responsabilidade e representação idênticas às dos Inspetores Regionais ${ }^{1}$, cujos cargos são extintos por este decreto-lei". Importante frisar que os delegados seriam "indicados pelo ministro de Estado e designados pelo Presidente da República"². De acordo com o decreto que criou as Inspetorias Regionais, as funções do inspetor eram, entre outras, gerir o órgão ao qual foi designado e autuar aqueles que infringissem os "dispositivos de todas as leis de assistência e proteção ao trabalho e respectivos regulamentos e julgar os recursos interpostos das que forem impostas por autoridades inferiores" 3 . Em suma, fiscalizar a aplicação das leis do trabalho nos ambientes laborais.

Valendo-se do exemplo de Muniz Falcão, primeiro delegado do Trabalho de Alagoas, podemos entender um pouco o peso político do cargo. Falcão exerceu a função em duas oportunidades: entre 26 de novembro de 1942 e 23 de novembro de 1945, retornando para mais um período entre 3 de março de 1947 e 21 de março de 1951. Na primeira vez, veio como figura-chave no processo de sindicalização do estado, então governado pelo interventor Ismar de Góis Monteiro. Com o fim do Estado Novo e as primeiras eleições do novo momento democrático, Muniz Falcão retornou para sua antiga função, dessa vez no mandato do irmão de Ismar, Silvestre Péricles. Só deixou de ser delegado do Trabalho para eleger-se deputado federal por duas vezes e, em 1955, Governador de Alagoas. Infelizmente, possuo poucas informações acerca da atuação de Muniz Falcão como delegado do Trabalho. Segundo Tenório, antes de ir para Alagoas em 1942, Muniz comandou a DRT de Sergipe. Antes de retornar a Alagoas em 1947, exerceu o cargo na Bahia, onde estava desde janeiro de $1946^{4}$.

\footnotetext{
${ }^{1}$ Sobre as Inspetorias, cf.: SOUZA, Samuel Fernando de. "Coagidos ou subornados": trabalhadores, sindicatos, Estado e as leis do trabalho nos anos 1930. 2007. 225 f. Tese (Doutorado em História) - Programa de PósGraduação em História Social, Universidade Estadual de Campinas, Campinas, 2007.

2 Artigos $2^{\circ}$ e $3^{\circ}$ do Decreto-Lei $n^{\circ}$ 2.168, de 6 de Maio de 1940, disponível em: http://www2.camara.leg.br/legin/fed/declei/1940-1949/decreto-lei-2168-6-maio-1940-412207publicacaooriginal-1-pe.html.

Artigo $18^{\circ}$ do Decreto $\mathrm{n}^{\circ}$ 22.244, de 22 de Dezembro de 1932, http://www2.camara.leg.br/legin/fed/decret/1930-1939/decreto-22244-22-dezembro-1932-526781publicacaooriginal-1-pe.html.

${ }^{4}$ TENÓRIO, Douglas Apratto. A tragédia do populismo - O impeachment de Muniz Falcão. $2^{\circ}$ ed. Maceió: EDUFAL, 2007, p. 272.
} 
Por lá, destacou-se por hostilizar a parcela mais combativa do movimento operário e sindical baiano ${ }^{5}$.

Sobre o sucessor de Muniz há mais informações. Edson Falcão ${ }^{6}$ seguiu um caminho diferente, pois nem chegou a ingressar na carreira política, mesmo sendo filiado ao PTB desde muito tempo ${ }^{7}$. Essa filiação partidária, inclusive, foi crucial em seu declínio à frente da DRT alagoana. Destarte, torna-se importante observar o PTB nesse contexto e entender melhor a atuação do delegado.

Segundo John French, "o PTB ainda se fundamentava nas velhas técnicas de clientelismo burocrático para a construção de seu novo partido 'popular'”. Para esse autor, o PTB surgiu de uma maneira análoga ao Partido Social Democrático (PSD), guardada as devidas proporções: formou-se de funcionários do aparelho estatal, igualmente clientelistas como os ex-interventores e funcionários públicos de cargos de prestígio que formariam o PSD. Acrescentem-se funcionários sindicais ligados ao corporativismo do sindicalismo oficial $^{8}$. Se a proposta era nova, as práticas eram antigas. Fernando Teixeira da Silva igualmente enxerga os resquícios de práticas antigas na criação do PTB, mas com um diferencial: a legenda serviria como um elo para manter o passado dentro da nova conjuntura política. Distanciando-se de outras agremiações surgidas no mesmo momento (sobretudo PSD e UDN), “o PTB significou uma proposta direcionada aos trabalhadores urbano-industriais em termos partidários". Para o autor, entre os objetivos da criação do PTB (como, por exemplo, se fazer presente nos sindicatos) estavam o controle de algumas instituições-chave do governo por seus membros, como Ministério do Trabalho, Justiça do Trabalho e Previdência Social ${ }^{9}$.

Da mesma forma que Muniz, Edson Falcão foi delegado do Trabalho em duas ocasiões, exercendo a função em duas conjunturas completamente distintas. Na primeira vez, ficou apenas um ano, entre 12 de outubro de 1953 e 27 de setembro de 1954. Depois voltou, atravessando praticamente toda a gestão de Muniz à frente do governo: reiniciou em 20 de fevereiro de 1956 e saiu no dia 24 de abril de 1959. Na primeira ocasião, Alagoas era governada por Arnon de Mello e não há muita documentação disponível sobre a atuação de

\footnotetext{
5 SOUZA, Edinaldo Antonio Oliveira. Trabalho, política e cidadania: trabalhadores, sindicatos e lutas por direitos (Bahia 1945-1964). 2015. 294 f. Tese (Doutorado em História) - Programa de Pós-Graduação em História, Universidade Federal da Bahia, Salvador, 2015, p. 106.

${ }^{6}$ Ter o mesmo sobrenome do ex-governador era apenas uma coincidência. Muniz e Edson não eram parentes.

${ }^{7}$ Entrevista com Thomas Edson Muniz Falcão concedida ao autor em 11 de julho de 2013. Não era apenas filiado, era militante ativo e um dos responsáveis por reerguer o partido na reabertura política na virada dos anos 1970 para os anos 1980 .

${ }^{8}$ FRENCH, John D. O ABC dos operários: conflitos e alianças de classes em São Paulo, 1900-1950. São Paulo: Hucitec / São Caetano do Sul: Prefeitura de São Caetano do Sul, 1995, p. 130.

${ }^{9}$ SILVA, Fernando Teixeira da. A carga e a culpa. Os operários das docas de Santos: direitos e cultura de solidariedade, 1937-1968. São Paulo: Hucitec; Santos: Prefeitura Municipal de Santos, 1995, p. 142.
} 
Edson Falcão nesse momento ${ }^{10}$. Por isso, é a sua segunda passagem pela DRT que passo a analisar neste artigo. Edson Falcão voltava ao cargo menos de um mês depois de Muniz Falcão ser empossado governador de Alagoas. Nesse início, era muito festejado, não apenas entre a classe trabalhadora, como também entre o governo.

\section{A harmonia}

Edson Falcão retornou à DRT em 1956 e duas semanas após ter reassumido o cargo, encaminhou-se até o bairro Fernão Velho, em Maceió. O motivo de sua visita: uma assembleia extraordinária realizada na sede social do Sindicato dos Trabalhadores na Indústria de Fiação e Tecelagem de Fernão Velho ${ }^{11}$, para que Falcão expusesse seu programa de trabalho. Mesmo com poucas informações na documentação, podemos intuir acerca de outros objetivos dessa visita. Entre os dois partidos criados pós-Estado Novo sob a influência direta do ex-ditador, coube ao PTB "veicular a proposta trabalhista de Vargas em termos partidários"12. Ir ao maior sindicato urbano de Alagoas expor seu programa de trabalho talvez estivesse incluído dentro da ideia de propagar o trabalhismo em terras alagoanas. Ainda por esse caminho, Lucília Neves Delgado destaca a relação do PTB com os sindicatos, principalmente por meio do que ela chama de "relação tríplice - movimento sindical, Ministério do Trabalho e PTB"13. Como membro filiado, Edson Falcão era parte importante dessa relação, pois representava, ao mesmo tempo, duas pontas do triângulo.

Convidado a compor a mesa da assembleia, Edson Falcão falou rapidamente acerca do seu programa de trabalho, "tendo oportunidade de ouvir várias reclamações dos associados sobre a perseguição no trabalho por parte da empresa, prometendo regular harmoniosamente a situação". Falcão "tomou nota das reclamações para uma posterior fiscalização" ${ }^{14}$. Sublinho a proposta de Falcão, de harmonia entre capital e trabalho, utilizando o espaço para divulgar uma das propostas de seu partido, ao invés de falar mais sobre as fiscalizações, apuração das

\footnotetext{
${ }^{10}$ Muita coisa foi-me contada por seu filho mais velho. De acordo com Thomas Falcão, seu pai saiu da DRT pela primeira vez por conta do ex-governador, de quem era inimigo político. Edson Falcão queria "ver o demônio, mas não queria ver" Arnon de Mello. Entrevista com Thomas Edson Muniz Falcão concedida ao autor em 11 de julho de 2013. Corroborando essa informação, temos uma pequena nota na primeira página de o Diário de Alagoas de agosto de 1957. O ex-governador moveu um "processo-crime" contra o delegado por injúria. Falcão teria chamado Mello de "desonesto", mas o júri popular absolveu o delegado. A nota encerra com uma provocação: “Como é Arnon, ainda teima em processar aos que lhe acusam de falcatruas?” JULGAMENTO DA OPINIÃO pública. Diário de Alagoas. Maceió, 10 ago. 1957, p. 1.

${ }^{11}$ Doravante Sindicato de Fernão Velho. Sindicato que representa os trabalhadores da Fábrica Carmen, uma das maiores e mais longevas indústrias têxteis de Alagoas.

12 GOMES, Angela de Castro e D'ARAÚJO, Maria Celina. Getulismo e trabalhismo. São Paulo: Editora Ática, 1989 , p. 9.

${ }^{13}$ DELGADO, Lucilia de Almeida Neves. PTB: do getulismo ao reformismo. São Paulo: Editora Marco Zero, 1989 , p. 75.

${ }^{14}$ Sindicato de Fernão Velho. Ata da reunião, 3 de mar. de 1956.
} 
denúncias e sua resolução dos embates dentro da lei em vigor que tanto defendia. Edson Falcão incorporava a ideia do Estado de harmonização dos conflitos, algo explícito na Justiça do Trabalho e em seu caráter conciliatório e no próprio PTB - nesse caso, não apenas de harmonia entre classes, como também a busca por uma "paz social", um dos objetivos de Getúlio Vargas com a criação desse partido ${ }^{15}$. Por outro lado, como membro ativo do PTB local, Edson Falcão incorporava (ou tentava) igualmente a ideologia primordial dos trabalhistas: "um grande partido de massas com bases sindicais"16. Há também nesse discurso o paternalismo típico dos petebistas, herdado diretamente do getulismo que fundou o partido.

Advogado, Edson Falcão entrou no mundo do trabalho por meio da DRT. Antes disso, só havia labutado como jornalista em seus tempos de estudante de Direito. Quando questionei seu filho sobre seu ingresso na delegacia, ele respondeu:

Acho que foi doutor Ari [Pitombo] quem [o] botou no Ministério, botou na delegacia. (...) Mamãe disse que parece que foi concurso quando ele foi pro Ministério. Agora, lá dentro eu sei que ele botou muita gente, pessoas correligionários, mas ele sempre foi dessa área política, ligado a doutor Ari Pitombo, a Silvestre Péricles, esse pessoal que era ligado ao PTB $^{17}$.

O líder trabalhista Ari Pitombo foi um dos mais conhecidos integrantes do PTB alagoano. Bem verdade que Pitombo foi membro fundador do PSD em Alagoas, pois era aliado e muito próximo do ex-interventor Ismar Monteiro. Contudo, já nas eleições de 1947, elegeu-se deputado estadual pelo PTB e assumiu algumas secretárias na gestão de Silvestre Péricles. Nos cinco pleitos seguintes, elegeu-se deputado federal pelo PTB (exceto em 1950, pelo PST de Péricles).

Sabemos que durante o período democrático, o Ministério do Trabalho sempre esteve nas mãos do PTB. Segundo Lucília Delgado, a existência "do PTB esteve profundamente ligada a dois tipos de instituições: os sindicatos e o Estado; a esse último através do Ministério do Trabalho". Sobretudo na gestão de Danton Coelho - entre janeiro e setembro de 1951 -, o Ministério assumiu "uma feição partidária, indelével"18.

Mais a frente, encontramos Edson Falcão novamente em Fernão Velho. Realizada no Recreio Operário, essa reunião teve como finalidade a posse da nova diretoria do sindicato. Acabou sendo discutido, também, o apoio e a defesa dos operários ao governador Muniz Falcão, representado aqui pelo delegado do Trabalho. Ao fim da sessão, Edson Falcão deixou

\footnotetext{
${ }^{15}$ DELGADO, op. cit., p. 103.

${ }^{16}$ GOMES e D'ARAÚJO, op. cit., p. 14.

17 Aqui vale uma correção: o ex-governador Silvestre Péricles não foi filiado ao PTB, mas era muito próximo dos trabalhistas de modo geral. Elegeu-se em 1947 pelo PSD e depois andou pelo PST e PDC. Entrevista com Thomas Edson Muniz Falcão concedida ao autor em 11 de julho de 2013

${ }^{18}$ DELGADO, op. cit., p. 294.
} 
claro que tanto a DRT como o Palácio dos Martírios estavam de portas abertas para os trabalhadores, prometendo cobrar dos patrões respeito pelas leis trabalhistas ${ }^{19}$. Essa proximidade do delegado com o governador demonstra um pouco da tentativa de coalizão nas eleições de 1955, quando os trabalhistas uniram-se em torno do nome de Muniz Falcão para o governo do estado ${ }^{20}$. Essa proximidade pode ser conferida também no periódico governista Diário de Alagoas.

Aniversaria, amanhã, o dr. Edson Falcão, Delegado Regional do Trabalho, no Estado de Alagoas e figura de destaque nos meios políticos, sociais e esportivos, do nosso Estado. (...) Além do cargo de Delegado Regional do Trabalho, o nosso companheiro de PTB, Dr. Edson Falcão, ocupa, ainda as funções de representante do Ministro do Trabalho, nos Conselhos Regionais do SESI, SENAI, SESC e SENAC, onde vem colaborando com os dirigentes das referidas entidades, em favor dos trabalhadores alagoanos ${ }^{21}$.

Nas comemorações do $1^{\circ}$ de Maio daquele ano, observamos a folha governista fazer vários elogios ao delegado, antes de anunciar o cronograma de atividades para aquele dia:

O Dr. Edson Falcão, Delegado Regional do Trabalho, tem-se caracterizado, à frente da repartição que dirige, não somente pela competência que lhe é inata, como pelas suas raras atitudes de verdadeiro Trabalhista.

No exercício das suas atividades, de par com a execução dos serviços rotineiros, jamais se esqueceu o ilustre Delegado do Trabalho de programar as festividades comemorando datas cívicas como a que hoje deflue, o DIA DO TRABALHO.

Afora os elogios, a programação feita por Falcão incluía desde a leitura da cartatestamento de Getúlio Vargas e momento para as lideranças sindicais discursarem, passando por sessões grátis de cinema, coquetel e duas partidas de futebol (uma entre os times das fábricas Carmen e da Saúde e a outra envolvendo um time baiano e a Seleção Alagoana) com a entrega das taças Dr. Edson Falcão e Governador Muniz Falcão, respectivamente. Por fim, uma sessão solene presidida pelo governador ${ }^{22}$.

Na edição seguinte ficamos sabendo como transcorreram as comemorações, as quais "alcançaram grande êxito". De acordo com a matéria de capa, os festejos foram organizados pela DRT, "auxiliada por entidades de classe" de Maceió, além da "participação destacada" do Sistema S (SESI, SENAI e SESC). Mostrando a importância da indústria têxtil, houve "salvas de 21 tiros" em praças da capital e nos bairros do Bom Parto, Saúde e Fernão Velho, onde localizavam-se as fábricas têxteis da capital. A reportagem destacou o espaço deixado na solenidade na parte da manhã para os próprios operários exporem seus problemas, tudo "sem

\footnotetext{
${ }^{19}$ Sindicato de Fernão Velho. Ata da reunião, 14 de abr. de 1956.

${ }^{20}$ Cf.: MOURA, Anderson Vieira. "“Uma candidatura de inspiração popular”: a formação da Frente Popular Alagoana (1955)". Cadernos de História. Belo Horizonte, v. 17, n. 27, 2016, p. 406-430.

${ }^{21}$ ANIVERSARIA, AMANHÃ, O Dr. Edson Falcão. Diário de Alagoas. Maceió, 7 abr. 1957, p. 6.

${ }^{22}$ HOJE: DIA DO Trabalho. Diário de Alagoas. Maceió, 1 mai. 1957, p. 3.
} 
sobressaltos de medidas restritivas da liberdade para a manifestação de suas justas reivindicações" ${ }^{23}$.

Ainda dentro das diretrizes do trabalhismo e do getulismo, em agosto de 1957 ocorreu no Palácio do Trabalhador um "Curso de Orientação Sindical, baseado na legislação trabalhista", organizado pela DRT. O curso contou "com a presença dos presidentes de sindicatos, delegações de Fernão Velho, Bom Parto, Rio Largo e Saúde”, bairros de concentração operária têxtil. Tanto o local do evento quanto "a praça fronteiriça ao Palácio do Trabalhador estavam totalmente lotados por compacta massa popular". Além de sindicalistas e trabalhadores, fizeram-se presentes o governador Muniz Falcão e Edson Falcão. O delegado do Trabalho convidou o governador para assumir "a presidência da sessão" e Muniz “deu por iniciados os trabalhos" ${ }^{24}$.

Três dias depois, a DRT organizou mais um "Curso de Orientação Sindical”, dessa vez na sede do Sindicato de Fernão Velho, "sob a responsabilidade direta do próprio Delegado do Trabalho, Dr. Edson Falcão" e novamente presidida pelo governador. A "meritória iniciativa" da DRT era apoiada pelo governador e, obviamente, Muniz Falcão não perdeu a oportunidade de estar diante dos "altivos e progressistas operários de Fernão Velho", sendo recebido de "maneira entusiasta e carinhosa". Não por menos, chegou ao local acompanhado da primeira dama Alba Mendes Muniz Falcão, de alguns secretários, parlamentares da sua base aliada e membros da imprensa. Havia um motivo para o excesso de discursos e "autoridades" no local: a "inauguração do retrato do presidente Juscelino Kubitschek, na sala de reuniões". A julgar pela reportagem, não houve "aula" nesse dia. Muniz fez seu discurso (resumido e bastante adjetivado pelo repórter) e depois todos seguiram para o Recreio Operário, onde foi servido um coquetel e os operários puderam se divertir e dançar ao som da sanfona e da voz marcante do Rei do Baião Luiz Gonzaga ${ }^{25}$. Em outra nota na mesma edição, ficamos sabendo que o evento foi uma espécie de "solenidade de abertura" do curso - por isso, toda pompa e circunstância.

Dois anos depois, em abril de 1958 era empossada uma nova diretoria do Sindicato de Fernão Velho - em uma sessão presidida pelo petebista Sizenando Nabuco, vice-governador de Alagoas, bastante satisfeito com o convite. Na mesma reunião seria entregue os certificados dos alunos do curso de orientação técnica ao trabalho. O delegado do Trabalho

\footnotetext{
${ }^{23}$ PALAVRAS DO GOVERNADOR aos trabalhadores: Jamais fui omisso e dúbio nos compromissos assumidos com os trabalhadores. Diário de Alagoas. Maceió, 3 mai. 1957, p. 1.

${ }^{24}$ APOIO DOS TRABALHADORES ao Governador. Diário de Alagoas. Maceió, 2 ago. 1957, pp. 1-2.

${ }^{25}$ APOTEÓTICA RECEPÇÃO AO Governador: Muniz ovacionado pelo operariado de Fernão Velho. Diário de Alagoas. Maceió, 6 ago. 1957, pp. 5-6.
} 
manifestou seu contentamento e entregou os certificados aos alunos ${ }^{26}$. No mês seguinte o tema da sessão ordinária era aumento salarial. Fizeram-se presentes, além de Edson Falcão, líderes sindicais de outras fábricas têxteis e, é claro, um grande número de associados. Após abrir os trabalhos, o delegado do Trabalho passou a palavra ao presidente, para que pudesse anotar as propostas dos presentes ${ }^{27}$.

O salto temporal na narrativa deu-se por causa da documentação. Por ora, vimos Edson Falcão participar de reuniões estratégicas, expor seu programa de atuação, promover cursos e entregar certificados, quase sempre compondo a mesa, porém nada de fiscalização nas fontes. Pelo menos até meados de 1958, Edson Falcão representava o Estado nos sindicatos urbanos de Alagoas. Não apenas o Estado: simbolizava também a pessoa de Muniz Falcão, com quem mantinha bom relacionamento. Apesar da desconfiança no olhar dos operários, o delegado se propunha a ser a ponte entre os trabalhadores e o governador. No entanto, em um determinado momento essa harmonia azedou e as coisas mudaram significadamente para ambos os lados.

\section{O conflito}

O Partido Comunista Brasileiro (PCB) local não compartilhava da empolgação do governador com o delegado do Trabalho, mesmo sendo os comunistas aliados de primeira linha de Muniz Falcão e próximos aos trabalhistas. Em seu estudo acerca do PTB, Lucília Delgado dá grande destaque ao anticomunismo (especialmente por parte de Vargas) como um fator importante na criação do PTB: seria o partido varguista a concorrer com o PCB pelos corações e mentes da massa de trabalhadores urbanos ${ }^{28}$. Destarte, o PTB seria o freio para o notável crescimento do PCB a partir de 1945 entre o eleitorado das cidades. Fernando Teixeira da Silva, ao analisar os objetivos da criação do PTB, tem opinião semelhante: “competir com o PCB, buscando absorver nos quadros do PTB os setores operários sob influência dos comunistas" ${ }^{29}$.

Em Alagoas, o delegado do Trabalho era aliado do governador, no mesmo instante em que o PCB tecia criticas a Edson Falcão. Nos fins de 1956, na Companhia de Fiação e Tecidos Norte Alagoas (Fábrica da Saúde), os patrões obrigaram os operários de três secções "a trabalharem uma média de dez a treze horas diárias", além de substituir "os trabalhadores de maior por menores". Dessa forma, os operários daquela localidade solicitavam "as

\footnotetext{
${ }^{26}$ Sindicato de Fernão Velho. Ata da reunião, 20 de abr. de 1958.

${ }^{27}$ Sindicato de Fernão Velho. Ata da reunião, 18 de mai. de 1958.

${ }^{28}$ DELGADO, op. cit., p. 49.

${ }^{29}$ SILVA, op. cit., p. 142.
} 
necessárias providências da Delegacia do Trabalho, enviando seus fiscais". A pequena nota encerra com críticas diretas ao órgão fiscalizador:

Não sabemos quando a Delegacia do Trabalho irá deixar de ajudar a provocar o fechamento das pequenas indústrias e passará a cuidar da fiscalização das grandes "Senzalas", como são os casos das usinas e fábricas de tecido.

Não sabemos também para que está servindo um corpo de fiscalização burocratizado e que somente dá expediente dentro daquela autarquia.

Será que estão fiscalizando os seus próprios funcionários? ? $^{30}$

As denúncias seguiam e, mais uma vez, não vemos os comunistas envolverem ou apelarem de alguma forma ao governador, então aliado da DRT. As críticas, ainda que não tenham assumido um tom mais duro, são dirigidas à delegacia e ao seu mandatário de forma isolada. O PCB estava completamente imerso na gestão de Muniz Falcão, blindando o governador de todas as maneiras possíveis. O PCB atacava com extrema cautela.

Somente a partir de 1958, quando Muniz reassumiu as rédeas do poder em Alagoas ${ }^{31}$, as relações entre governo e DRT modificaram-se profundamente. A primeira indicação remete-nos a abril. Na posse da nova diretoria do Sindicato dos Trabalhadores das Indústrias de Fiação e Tecelagem Floriano Peixoto ${ }^{32}$, além da presença dos trabalhadores da localidade e uma delegação vinda de Fernão Velho, compareceram o diretor geral da fábrica, Antonio Nogueira, o delegado do Trabalho e Odilon de Souza Leão Filho, Secretário de Viação e Obras Públicas e representante do governador Muniz Falcão. A mudança do representante, nesse momento, pode não indicar uma ruptura entre governador e delegado - apesar do repórter de o Diário de Alagoas comentar com certa frieza a presença de Edson Falcão no evento $^{33}$.

Ao contrário do ano anterior, as comemorações do dia $1^{\circ}$ de Maio, organizadas pelo Palácio dos Martírios, não contariam com o delegado do Trabalho - muito menos na cobertura feita pela folha governista. A matéria - com o sugestivo título de "O dia Primeiro de Maio será inédito" - anunciava "os responsáveis pelos festejos": Djalma Falcão (irmão do governador), Napoleão Barbosa (presidente da Federação das Indústrias do Estado de Alagoas - FIEA) e Osvaldo Veloso (presidente da Federação dos Trabalhadores nas Indústrias de Alagoas). Entretanto, ficamos sabendo apenas que os responsáveis tentavam trazer um time de Recife para duas partidas amistosas em Maceió e "uma caravana de artistas do Recife, que

\footnotetext{
${ }^{30}$ VOZES DAS FÁBRICAS - De Saúde. A Voz do Povo. Maceió, 28 out. 1956, p. 3.

${ }^{31}$ Em 1957, sofreu um processo de impeachment. Cf.: TENÓRIO, op. cit., 2007.

32 Doravante Sindicado de Saúde. A homenagem ao marechal de ferro deu-se porque Floriano nasceu em Ipioca, distrito maceioense formado por alguns povoados, quase todas praianos. A Saúde é uma dessas localidades sem acesso para o mar.

${ }^{33}$ POSSE FESTIVA DA diretoria do sindicato operário de Saúde. Diário de Alagoas. Maceió, 2 abr. 1958 , p. 6.
} 
se apresentaria em 'shows' para os trabalhadores" ${ }^{\prime 34}$. Um conteúdo um pouco diferente dos festejos organizados por Edson Falcão, principalmente por dois detalhes.

Primeiro: pela "primeira vez" desde a posse de Muniz, "o Governo do Estado toma a

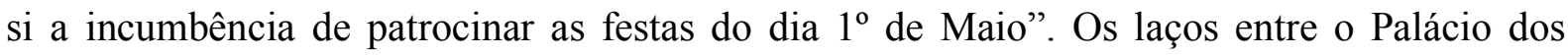
Martírios e a Delegacia Regional do Trabalho pareciam ser bem maiores, fazendo com que o governador "terceirizasse" a organização dos festejos. Não podemos esquecer que "o sr. Muniz Falcão exerceu, por vários anos, o cargo de Delegado Regional do Trabalho, em Alagoas, cargo esse em que se houve com dignidade, praticando a verdadeira justiça social". Talvez Muniz Falcão fosse avesso a comemorações lúdicas. Segundo detalhe: foi mantida a salva de 21 tiros, o hasteamento da bandeira e a execução do Hino Nacional pela banda da Polícia Militar, porém não houve a leitura da carta-testamento de Getúlio Vargas, ideia do getulista Edson Falcão. Da mesma forma, as lideranças sindicais e os trabalhadores não tiveram espaço para discursar em praça pública. No lugar disso, agendou-se uma "visita das delegações sindicais ao Governo do Estado, no Palácio" "35.

Os únicos a discursar após o hasteamento da bandeira e execução dos hinos Nacional e de Alagoas foram Osvaldo Veloso, o professor José Cajueiro (segundo a matéria, falou em nome do governador, mas quem o representou oficialmente foi o secretário José de Campos) e o jornalista Nilson Miranda, dirigente do PCB local. Em seu discurso, Miranda "pregou a união dos trabalhadores como condição indispensável à conquista de objetivos correspondentes aos seus direitos" e, ao final, solicitou aos ouvintes "que se dirigissem ao Palácio Marechal Floriano, onde seriam recebidos pelo Governador Muniz Falcão" ${ }^{\text {" }}$.

Edson Falcão começou a ser duramente criticado pelas principais lideranças à frente da Federação dos Trabalhadores, órgão ligado diretamente à Confederação Nacional dos Trabalhadores na Indústria (CNTI) - os principais líderes da Federação local foram delegados da CNTI em Alagoas. Prevista pelo $\S 2^{\circ}$ do Artigo 535 da CLT, a CNTI veio ao mundo pelo Decreto $n^{\circ} 21.978$, de 25 de outubro de 1946, em pleno governo Dutra. Em resumo, era um órgão completamente atrelado ao Estado. Devido à atuação de seus líderes ao longo da década de 1950, não era bem vista entre os nomes mais combativos do sindicalismo principalmente do Sudeste brasileiro. Segundo Kenneth Erickson, essa situação mudou apenas com a ascensão de Goulart à presidência. O brasilianista também demonstra uma das "funções" do órgão:

\footnotetext{
${ }^{34}$ O DIA PRIMEIRO de Maio será inédito. Diário de Alagoas. Maceió, 19 abr. 1958, p. 6.

${ }_{35}^{35}$ COMEMORAÇÃO FESTIVA DO $1^{\circ}$ de Maio. Diário de Alagoas. Maceió, 29 abr. 1958, p. 6.

${ }^{36}$ PROMOVIDAS PELO GOVERNO decorreram brilhantes as festas de $1^{\circ}$ de Maio. Diário de Alagoas. Maceió, 3 mai. 1958, pp. 1-2.
} 
A oportunidade para um afastamento definitivos dos pelegos mais impopulares veio com a eleição bienal para a CNTI, quando Goulart colocou o poder da presidência por trás dos homens que o haviam apoiado três meses antes. Goulart veio ao Rio para o congresso da CNTI e organizou então o afastamento dos pelegos. Os pelegos ocupantes dos cargos-chave exerciam influência sobre os delegados eleitores porque seus postos na Confederação permitia-lhes distribuir oportunidades de viagem, empregos e outros favores $^{37}$.

Possivelmente em função disso (atrelamento ao Estado e lideranças consideradas pelegas), não há muitos estudos e referências bibliográficas acerca da Confederação. No entanto, é a entidade sindical com maior destaque entre os trabalhadores alagoanos na segunda metade da década de 1950, o que poderia indicar pistas mais gerais do sindicalismo no estado.

Após as comemorações do $1^{\circ}$ de Maio em 1958, as relações entre governo e DRT romperam-se em definitivo. Em sua reportagem, os comunistas iniciam um texto adjetivando o delegado de "atrabiliário" [sic] e expondo a "medida absurda e arbitrária" tomada por Edson Falcão: uma intervenção na Federação dos Trabalhadores na Indústria de Alagoas, sob a suposta alegação de que a entidade estava "acéfala", empossando uma Junta Governativa. O periódico do PCB vai além, descortinando o viés político da intervenção: com apoio de alguns “divisionistas", Edson Falcão tentava "transformar o Palácio do Trabalhador em sede de sua campanha política" em prol de Ari Pitombo. Em um manifesto redigido pelos presidentes de três sindicatos filiados à Federação (Construção Civil, Metalúrgica e Mecânica de Maceió e Óleo Vegetais e Animais de Alagoas) há mais informações. No dia 26 de maio ocorreram as eleições da entidade, com duas chapas inscritas, sendo o resultado final um empate com quatro votos para cada um. Em reunião, Edson Falcão afirmou não ter sido comunicado oficialmente pela Federação do resultado, "quando nós temos em nosso poder, cópia dos dois ofícios, enviado ao Delegado do Trabalho" 38 .

Os antigos aliados do delegado consideraram suas atitudes ditas arbitrárias como sendo "lesivas aos interesses da classe trabalhadora". Não reconhecendo a Junta Governativa, membros da Federação contrários à atitude "se dirigiram ao Ministério do Trabalho, comunicando as razões do seu protesto e solicitando as providências que o caso requer" ${ }^{39}$. Por

\footnotetext{
${ }^{37}$ ERICKSON, Kenneth Paul. Sindicalismo no processo político no Brasil. São Paulo: Editora Brasiliense, 1979, p. 148. Grifos meus.

${ }^{38}$ ATO ARBITRÁRIO DO Delegado do Trabalho na Federação dos Trabalhadores. A Voz do Povo. Maceió, 8 jun. 1958 , p. 4.

${ }^{39}$ O DELEGADO REGIONAL do Trabalho contra interesses dos trabalhadores alagoanos. Diário de Alagoas. Maceió, 5 jun. 1958, p. 6.
} 
outro lado, não houve esclarecimentos por parte dos representantes de como ficou a entidade após o empate nas eleições.

Apenas três dias depois da publicação da denúncia ficamos sabendo o desfecho das eleições. Em entrevista ao Diário de Alagoas, o líder sindical José Luiz citou a portaria 146, datada de 18 de outubro de 1957: "No caso de empate o Presidente da mesa [Osvaldo Veloso] comunicará ao Ministro do Trabalho, Indústria e Comércio, para que este designe nova data para o pleito". José Luiz defendeu Veloso, assegurando possuir cópias dos ofícios enviados à DRT. A portaria por si só demonstra um forte atrelamento da Federação ao Estado e ao Ministério do Trabalho, controlado pelo PTB. Ainda de acordo com o representante da CNTI, “o Sr. Delegado, verificando que a chapa na qual tinha interesse não fora eleita, procurou fazer o seu jogo, lançando trabalhadores contra trabalhadores, por meio de intrigas mesquinhas". Por outro lado, parece haver uma incoerência entre as matérias dos dois jornais e a entrevista de José Luiz. Em sua fala, este afirmou: "Se a Federação dos Trabalhadores estava acéfala, como disse o Sr. Delegado do Trabalho, porque não determinou a intervenção, como manda a Consolidação das Leis do Trabalho?"40 Afinal, era uma prerrogativa do Ministério poder "intervir nos assuntos internos de uma organização sindical, indicando um delegado ou junta para administrá-la”. Edson Falcão, na qualidade de delegado do Trabalho, era exatamente o representante do Ministério em Alagoas. E não foi isso exatamente o que aconteceu? Houve o pleito, o resultado final foi um empate e o presidente avisou ao Ministério para que se marcasse nova eleição. Ao empossar uma Junta Governativa, Edson Falcão acabou por destituir Osvaldo Veloso, pois enquanto não se realizasse um novo pleito, Veloso continuaria na presidência - ou teria que sair, deixando a entidade "acéfala". A possibilidade de intervenção ministerial não era aleatória, acontecia "apenas em caso de desacordo interno ou outras circunstâncias que impediam seu funcionamento normal, e os interventores permaneceriam somente o necessário para restaurar a atividade normal" ${ }^{41}$. José Luiz referia-se ao Artigo 528 da CLT:

\begin{abstract}
"Ocorrendo dissídios ou circunstâncias que perturbem o funcionamento do sindicato, o ministro do Trabalho, Indústria e Comércio poderá nele intervir, por intermédio de delegado com atribuições para administração da associação e executar ou propor as medidas necessárias para normalizar-lhe o funcionamento".
\end{abstract}

Fica cada vez mais claro que essas desavenças não passavam de problemas políticopartidários, como os envolvidos alegaram mais de uma vez.

\footnotetext{
${ }^{40}$ A POLÍTICA NA Delegacia do Trabalho fere a autonomia da Fede. Dos Trabalhadores. Diário de Alagoas. Maceió, 8 jun. 1958, p. 6.

${ }^{41}$ ERICKSON, op. cit., p. 65
} 
Osvaldo Veloso foi pessoalmente até a capital federal comunicar o ocorrido a Parsifal Barroso, ministro do Trabalho. E do Rio de Janeiro, Veloso mandou um telegrama aos seus correligionários informando o resultado de sua visita: a diretoria atual (ou seja, ele próprio) deveria permanecer no cargo devido ao impasse no pleito. Dessa forma, chegava ao fim "a intervenção ilegal do Delegado do Trabalho" "42. Ao menos legalmente. Os aliados governistas não cessaram as críticas à intervenção considerada indevida do delegado. José Luiz, representante da CNTI em Alagoas, mostrou-se confiante numa resolução dentro da lei para a questão, tecendo elogios a Parsifal Barroso ${ }^{43}$. O ministro, por seu turno, não decepcionou: em telegrama enviado à DRT, confirmou Osvaldo Veloso na presidência da Federação, determinando que "as eleições marcadas pelo referido delegado para sábado próximo vindouro" não procediam ${ }^{44}$.

A partir de meados de março de 1959, o Diário de Alagoas parecia adivinhar o que estava por acontecer, pois não enfeitava mais o seu discurso contra Edson Falcão. Classificou suas atitudes nos últimos meses como criminosa ("pelo seu sentido agitacionista") e impatriótica (afinal, naquele momento, o Brasil necessitava "de ordem e tranquilidade"). O jornal não mais escondia: Falcão deveria deixar sua função. O novo ministro do Trabalho, Fernando Nóbrega, enviou ao estado um representante, Rubens Prazeres, com a função de “gerir os negócios da Federação dos Trabalhadores de Alagoas, e realizar o pleito para renovação da Diretoria (...)" ${ }^{\text {45 }}$. Em outras palavras, uma intervenção, como mandava a lei. Ao menos essa parecia ter o apoio dos aliados governistas.

O desfecho desse embate entre DRT e Federação não poderia ser menos dramático: “Alarmado com a marcha dos acontecimentos que deliberadamente provocou, o Delegado do Trabalho viajou apressadamente para o Rio de Janeiro, embarcando a bordo do navio

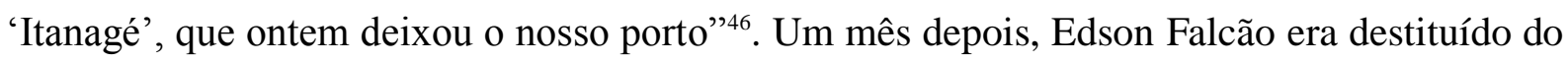
cargo.

As notícias acerca das eleições e da própria Federação cessaram no jornal governista, mas não o desentendimento com setores do PTB. Dois meses depois, o Diário de Alagoas resolveu deixar claro o motivo de sua desavença com uma parte do PTB. Em um artigo no topo da primeira página, o periódico publicou severas críticas ao deputado Ari Pitombo. No

\footnotetext{
${ }^{42}$ PERMANECERÁ A DIRETORIA legitima da Federação dos Trabalhadores. Diário de Alagoas. Maceió, 15 jun. 1958, pp. $1 ; 5$.

${ }_{43}$ DELEGADO DO TRABALHO quer utilizar o sindicalismo para interesses políticos. Diário de Alagoas. Maceió, 17 jun. 1958, pp. 1-2.

${ }^{4}$ MANTIDO OSVALDO VELOSO. Diário de Alagoas. Maceió, 20 jun. 1958, p. 1.

${ }^{45}$ DELEGADO DO TRABALHO coagiu operários. Diário de Alagoas. Maceió, 19 de mar. 1959, pp. 1; 2.

${ }^{46}$ ALARMADO COM A luta que desfechou no meio sindical, Delegado do Trabalho viajou ao Rio. Diário de Alagoas. Maceió, 20 de mar. 1959, pp. 1; 5.
} 
penúltimo parágrafo, as mágoas passadas são descortinadas: "Depois de haver traído miseravelmente os alagoanos, bandeando-se para o lado daqueles que pretenderam cassar o mandato do Governador Muniz Falcão, um mandato que pertence ao povo (...) ${ }^{\text {\$4 }}$.

O jornal igualmente não esqueceu o antigo aliado do governador, agora ex-delegado do Trabalho. Muito pelo contrário: além de ressentimento, demonstrava uma profunda antipatia por Edson Falcão. Vale ressaltar que, após a saída de Falcão (abril de 1959), a DRT alagoana ficou dois anos sem delegado. Talvez em razão disso o jornal governista afirmasse que os fatos narrados na reportagem sejam inspirados no ex-delegado. Isso fica claro na primeira frase do texto: "Volta a Delegacia do Trabalho a intervir ostensivamente nos sindicatos". Para o repórter, o momento não era dos melhores, com "a vida sindical em Alagoas" a beira de um "colapso devido à má administração aqui instaurada pelo representante do PTB". Ou seja, os problemas sindicais no estado eram culpa única e exclusiva do delegado do Trabalho, superestimando suas atribuições e até mesmo a influência, inserção e poder do órgão fiscalizador. Vendo de outro modo, podemos entender que, para o jornal, a Federação dos Trabalhadores era a expressão máximo do sindicalismo alagoano: com os problemas na sucessão da entidade e a consequente intervenção, toda a vida sindical no estado terminava por perecer lentamente.

Havia uma perseguição de certa forma desmedida feita pela folha a Edson Falcão, como podemos ver logo no segundo parágrafo: “Apesar de, noutras épocas, o sindicalismo em Alagoas ter sido bastante florescente, nos últimos anos a vida sindical enfraqueceu muito em face do comportamento (...) do Sr. Edson Falcão”. Como se não bastasse, o próprio periódico governista atesta a ineficácia da política sindical do Palácio dos Martírios, pois os últimos anos do enfraquecimento da "vida sindical" alagoana aconteceram justamente no governo Muniz Falcão. A ânsia em criticar Edson Falcão era tamanha que acabava por revelar a frágil atuação de Muniz Falcão no campo sindical, justamente o governador que, segundo o próprio jornal, entendia como poucos os problemas dos trabalhadores ${ }^{48}$.

Nos primeiros dias de novembro de 1959, ocorreu, enfim, um novo pleito para a escolha da diretoria da Federação. E para tal evento, temos matéria dos dois periódicos rivais - Gazeta de Alagoas (União Democrática Nacional) e Diário de Alagoas (Partido Social Progressista, partido do governador Muniz Falcão) -, com conteúdos completamente distintos; apenas o resultado final é o mesmo. De acordo com a matéria do jornal udenista, no

\footnotetext{
${ }^{47}$ PITOMBADAS DO ARY. Diário de Alagoas. Maceió, 22 de mai. 1959, p. 1.

${ }^{48}$ EX-DELEGADO DO TRABALHO quis encobrir falcatrua no Sindicato de Fernão Velho. Diário de Alagoas. Maceió, 11 de ago. 1959, pp. 1; 5.
} 
dia marcado, o presidente do Sindicado de Saúde desapareceu; entretanto, não houve rapto, somente "por uma questão de precaução, foragiu-se para que pudesse comparecer" no local de votação. Sua astúcia funcionou e ele conseguiu votar. As atenções se voltaram para o inspetor da DRT, José da Cunha Gomes, "a quem caberia presidir a Mesa Eleitora”: no dia da eleição, José Gomes foi preso e transportado para a cidade de Arapiraca, por “ordem do Secretário da Segurança Pública". Coube ao suplente Helio Bezerra (“funcionário do Ministério do Trabalho") presidir o pleito e a Celso Mendes, promotor da $6^{\circ}$ Região enviado pelo próprio ministro do Trabalho, presidir a apuração. Por meios coercitivos, Muniz Falcão conseguiu impor sua vontade e elegeu seu candidato ${ }^{49}$.

Nada disso é narrado na versão do Diário de Alagoas, publicada dois dias antes da matéria acima (e no dia posterior ao pleito). Não há prisão, desaparecimento de líder sindical ou qualquer tipo de balbúrdia: a eleição aconteceu em um "ambiente de camaradagem e compreensão, numa prova inconteste de que os trabalhadores de Alagoas estão realmente unidos, nada adiantando os malabarismos do Sr. Edson Falcão para dividir a classe”. Não sabemos o real clima do evento, posto que um jornal desejava apenas criticar o governador e o outro o ex-delegado do Trabalho. Todos os 15 sindicatos com direito a voto compareceram no horário marcado. A chapa governista era encabeçada por Joel dos Santos e a "oposição" por Aquino Japiassú (apenas este é citado pela Gazeta de Alagoas; Joel aparece como candidato governista). Ao final da contagem, Joel venceu por nove votos a seis. A posse da diretoria eleita aconteceu no dia seguinte, novamente presidida por Celso Mendes. Após o evento, o grupo marchou até o Palácio dos Martírios para hipotecar solidariedade a Muniz Falcão, "verdadeiro amigos do trabalhador alagoano" 50 .

Como Edson Falcão não estava mais na DRT, as informações sobre o órgão no periódico governista chegaram ao fim, ficando ainda mais claro que o interesse do jornal na DRT dependia exclusivamente da presença de Falcão por lá. Mesmo quando eram aliados, não encontramos nas fontes a DRT fazendo seu papel: intermediando conflitos, apurando denúncias, fiscalizando os locais de trabalho. Até mesmo nos processos trabalhistas pesquisados a DRT raramente aparece e quando o faz é exercendo um papel secundário: informando quando é requisitada pelos juízes. Como desejavam as lideranças trabalhistas, não houve intermediação de conflitos entre capital e trabalho.

\footnotetext{
${ }^{49}$ FUNCIONÁRIO DA DELEGACIA do Trabalho Foi Preso Para o Governador Vencer Eleições Trabalhistas. Gazeta de Alagoas. Maceió, 08 de nov. 1959, p. 6.

${ }^{50}$ ONTEM: TRABALHADORES ALAGOANOS Elegeram a Nova Diretoria da Federação. Diário de Alagoas. Maceió, 06 de nov. 1959, pp. 1-2.
} 
Para compor esse texto, além dos "habituais" problemas e dificuldades em relação ao acesso à documentação da DRT alagoana, esbarrei na falta de pesquisas sobre as delegacias do Trabalho em todo o país. Uma análise mais acurada da DRT enquanto instituição é dificultada pela escassez de estudos dedicados às delegacias, como destaquei logo no início. Há pesquisas sobre os primórdios das leis trabalhistas, sobre as Inspetorias Regionais ${ }^{51}$ e a criação e trajetória do Ministério do Trabalho. Mais forte são os trabalhos sobre a Justiça do Trabalho, que merecidamente "ganhou cidadania acadêmica e merece ser interpretada a partir de seus próprios objetivos, intenções e práticas, assim como de seus limites e contradições" 52 . Resta agora os pesquisadores debruçarem-se também sobre as DRT e inseri-las no contexto macro que envolve toda a Justiça Trabalhista e o período democrático.

\footnotetext{
${ }^{51}$ Esses são os melhores oásis, pois, como vimos no início, não houve mudanças significativas entre o fim das Inspetorias e o começo das delegacias.

${ }^{52}$ GOMES, Ângela de Castro e SILVA, Fernando Teixeira da. "Os direitos sociais e humanos dos trabalhadores no Brasil: a título de apresentação". In: GOMES, Ângela de Castro e SILVA, Fernando Teixeira da (org.). A Justiça do Trabalho e sua história: os direitos dos trabalhadores no Brasil. Campinas: Editora da UNICAMP, 2013, p. 36
} 


\section{FONTES}

A Voz do Povo (jornal).

Diário de Alagoas (jornal).

Gazeta de Alagoas (jornal).

Entrevista com Thomas Edson M. Falcão concedida ao autor em 11 de julho de 2013.

Sindicato dos Trabalhadores na Indústria de Fiação e Tecelagem de Fernão Velho. Atas de reuniões ordinárias, 1956 e 1958.

\section{BIBLIOGRAFIA}

COSTA, Hélio da. Em busca da memória: comissão de fábrica, partido e sindicato no pósguerra. São Paulo: Scritta, 1995.

DELGADO, Lucilia de Almeida Neves. PTB: do getulismo ao reformismo. São Paulo: Editora Marco Zero, 1989.

ERICKSON, Kenneth Paul. Sindicalismo no processo político no Brasil. São Paulo: Editora Brasiliense, 1979.

FRENCH, John D. O ABC dos operários: conflitos e alianças de classes em São Paulo, 19001950. São Paulo: Hucitec / São Caetano do Sul: Prefeitura de São Caetano do Sul, 1995.

GOMES, Angela de Castro e D'ARAÚJO, Maria Celina. Getulismo e trabalhismo. São Paulo: Editora Ática, 1989.

GOMES, Ângela de Castro e SILVA, Fernando Teixeira da. "Os direitos sociais e humanos dos trabalhadores no Brasil: a título de apresentação". In: GOMES, Ângela de Castro e SILVA, Fernando Teixeira da (org.). A Justiça do Trabalho e sua história: os direitos dos trabalhadores no Brasil. Campinas: Editora da UNICAMP, 2013.

LEAL, Murilo. A reinvenção da classe trabalhadora (1953-1964). Campinas: Editora da Unicamp, 2011.

MAJELLA, Geraldo de. Mozart Damasceno, o bom burguês. Recife: Edições Bagaço, 2011.

MOURA, Anderson Vieira. "Os trabalhadores também são notícia: a relação dos operários alagoanos com os jornais nos anos 1950”. Revista Crítica Histórica, Ano V, nº 9. Maceió: UFAL/ICHCA, 2014.

. “Uma candidatura de inspiração popular": a formação da Frente Popular Alagoana (1955)". Cadernos de História. Belo Horizonte, v. 17, n. 27, 2016, p. 406430.

SILVA, Fernando Teixeira da. A carga e a culpa. Os operários das docas de Santos: direitos e cultura de solidariedade, 1937-1968. São Paulo: Hucitec; Santos: Prefeitura Municipal de Santos, 1995. 
SOUZA, Edinaldo Antonio Oliveira. Trabalho, política e cidadania: trabalhadores, sindicatos e lutas por direitos (Bahia 1945-1964). 2015. 294 f. Tese (Doutorado em História) - Programa de Pós-Graduação em História, Universidade Federal da Bahia, Salvador, 2015.

SOUZA, Samuel Fernando de. "Coagidos ou subornados": trabalhadores, sindicatos, Estado e as leis do trabalho nos anos 1930. 2007. 225 f. Tese (Doutorado em História) - Programa de Pós-Graduação em História Social, Universidade Estadual de Campinas, Campinas, 2007.

TENÓRIO, Douglas Apratto. A tragédia do populismo - O impeachment de Muniz Falcão. $2^{\circ}$ ed. Maceió: EDUFAL, 2007. 